\title{
Linguistic focus affects eye movements during reading
}

\author{
STACY BIRCH and KEITH RAYNER \\ University of Massachusetts, Amherst, Massachusetts
}

\begin{abstract}
In two experiments, we explored how readers encode information that is linguistically focused. Subjects read sentences in which a word or phrase was focused by a syntactic manipulation (Experiment 1) or by a preceding context (Experiment 2) while their eye movements were monitored. Readers had longer reading times while reading a region of the sentence that was focused than when the same region was not focused. The results suggest that readers encode focused information more carefully, either upon first encountering it or during a second-pass reading of it. We conclude that the enhanced memory representations for focused information found in previous studies may be due in part to differences in reading patterns for focused information.
\end{abstract}

Researchers in language processing have explored how people access, remember, and use information during language comprehension. Given the limitations of human information-processing capabilities, an important aspect of successful language comprehension involves selectivity in what is encoded and retained from sentence to sentence. Some information becomes more available for use in interpreting subsequent sentences, while other information becomes less available. Typically, selectivity in what is attended to and retained is based on salience: concepts that are perceived as important are attended to more closely than other information, since these concepts seem likely to be the ones that will be needed for understanding forthcoming information. One factor that affects perceived importance or salience of information within sentences is linguistic focus.

The term "focus" has been used by researchers in artificial intelligence, linguistics, and psycholinguistics to describe a number of related phenomena. As used in this paper, the focus of a sentence consists of the information that is newly asserted in a discourse, sometimes contrastive, and is most prominent or emphasized within the sentence (Chomsky, 1971; Halliday, 1967; Rochemont \& Culicover, 1990). Focus is conveyed by such things as spoken accent (prosodic information) and nontypical sentence structures (syntactic information; see Rochemont $\&$ Culicover, 1990). For example, in the spoken sentence HILDY kissed Tom, Hildy is focused by being accented (capitalization denotes accenting). And in the sentence

Portions of this research were reported at the 1994 meeting of the Psychonomic Society, St. Louis. The research was supported by Grant DBR-9121375 from the National Science Foundation. The first author was supported by an NIH postdoctoral fellowship (Grant 2T32HD/07327), and the second author was supported by an NIMH Research Scientist Award (Grant MH 01255). We thank Charles Clifton, Susan Garnsey, and Shelia Kennison for helpful comments on a previous version of this paper. Requests for reprints should be addressed to S. Birch, School of Cognitive Science, Hampshire College, Amherst, MA 01002 (e-mail: sbirch@hampshire.edu).
It was Hildy who kissed Tom, Hildy is focused by virtue of its position as the clefted element in the cleft sentence, which is a syntactic focusing structure.

The language-processing consequences of manipulating sentence focus have been investigated in a number of studies. Researchers have found, for example, that listeners detect focused information more quickly (Cutler \& Fodor, 1979) and more accurately (e.g., Hornby, 1974), and they remember it better (Gernsbacher \& Jescheniak, 1995; Singer, 1976) than they do nonfocused information. In reading, which will be the concern here, syntactic manipulations of focus can lead to effects that are similar to those found in the auditory domain. For instance, readers are more likely to detect errors when they are part of the sentence focus (Bredart \& Docquier, 1989; Bredart \& Modolo, 1988), and they show enhanced memory for focused concepts (Birch \& Garnsey, 1995; Carpenter \& Just, 1977b). These studies show that linguistic focus has a strong impact on the memory representation of sentences. However, little is known about how readers encode focused information and how they are able to retain it better. In this study, we investigated the effects of focus on readers' eye movements to learn what reading patterns or strategies might contribute to the effects found in earlier focus experiments.

We begin by discussing relevant findings from previous experiments. In one study of focus effects on eyemovement behavior, subjects visually inspected pictures that corresponded to a preceding sentence (Zimmer \& Engelkamp, 1981). They listened to cleft sentences that focused one of two people and then viewed pictures of both people, one at a time. The subjects spent a longer time looking at the picture of the person who had been focused in the preceding sentence. This result suggests that the clefted or focused referent from the sentence was considered to be more important, and that subjects spent a longer time viewing the picture of the more important referent.

More recently, Sedivy, Carlson, Tanenhaus, SpiveyKnowlton, and Eberhard (1995) also investigated auditory 
focus effects on eye-movement patterns during inspection of a visual display (also see Tanenhaus, SpiveyKnowlton, Eberhard, \& Sedivy, 1996). Sedivy et al. used contrastive stress to manipulate focus. They found that when an object in the display was focused, that is, referred to with contrastive stress (e.g., "the SMALL blue circle"), eye movements to the object were faster than when the object was not focused. Also, a subsequent reference to the other, "contrast member" of a set (e.g., the large blue circle) resulted in eye movements to that contrast member that were faster than they were when the first object was not focused. Sedivy et al. argued that reference resolution of the focused object and the contrast member were facilitated by contrastive stress in referring to the first object. Thus, focus can affect accessibility of the referents of objects and closely related objects, and this effect can be gauged by eye-movement data.

In a study monitoring the eye movements of readers, Carpenter and Just (1977b) investigated how a pronoun in a current sentence affected regressions to antecedent information in a previous sentence. The pronoun was always ambiguous between two possible antecedents from a preceding sentence. Carpenter and Just manipulated the content of the sentences preceding the pronoun, and the way one of the referents of the pronoun was introduced. In the focus condition, one of the referents was syntactically focused (by a cleft or pseudocleft construction), and in the other, control condition, neither referent was focused. They hypothesized that readers would be more likely to make a regression to the antecedent when they encountered the pronoun following a focused antecedent than they would when it had not been focused. Carpenter and Just claimed that their results supported that view, but this claim may not be warranted, since fixation regions were not equivalent for the two conditions. A more informative result involved the regressions to the nonfocused antecedent, which was the same in both conditions. When one concept was focused, there were about half as many regressions to the nonfocused antecedent as there were in the control condition. This result indicates that upon encountering an ambiguous pronoun, readers are less likely to refixate a potential antecedent when another antecedent has been focused. It seems likely that readers also refixate a focused antecedent more often than they do when there is no focused antecedent, although this result has yet to be confirmed.

In another eyetracking experiment, Scinto (1978) compared readers' fixation patterns while they were reading information that was newly introduced versus information that had been mentioned in preceding sentences within a story. Scinto divided the story to be read into regions and classified each region as either new or given, depending on whether the information in the region had or had not been mentioned in a preceding region. He presented the story to 5 subjects, monitored their eye movements while they read, and compared the number and duration of fixations for given versus new regions. Scinto found that there were more fixations and longer fixation durations in the new versus the given regions, which would suggest that readers generally spent more time processing information that was newly introduced. However, this conclusion is undermined by the differences between the new and given regions in Scinto's experiment. Because the content of these regions was not equivalent, it is impossible to say whether increased processing time arose from new-given status or from other differences between the information in the regions (e.g., word frequency, which is known to have a strong effect on fixation durations; see Rayner \& Duffy, 1986).

The present study was intended to provide evidence of encoding differences during reading for focused and nonfocused information, and to describe the nature of any observed differences. If it is true that sentence focus, by signaling prominence or importance of concepts, leads readers to retain those concepts better, or perhaps mark them as "privileged" in their representation, then their eye-movement record should tell us something about the encoding of important information. On the basis of studies in visual attention and object recognition, Berlyne (1966) proposed that, among other things, newness and significance were sources of attention. He observed that objects that were attended to because of such properties should be fixated more often and for longer durations (see also Berlyne, 1958; Mackworth \& Morandi, 1967). For the present study of reading, we have explored whether concepts marked as important by linguistic structure lead to similar fixation patterns.

In the two experiments reported here, subjects read sentences that varied according to whether or not a word or phrase was focused. Subjects' eye movements were monitored while they read. We measured the effects of focus on first-pass processing and reprocessing of the sentences, and in particular of the focused concepts as compared with their nonfocused counterparts. To the extent that readers identify focused information as important information that should be carefully attended to, the expectations were that readers would spend a longer time reading focused information during first-pass processing and/or during reprocessing.

\section{EXPERIMENT 1}

In Experiment 1, focus was manipulated with syntactic focusing phrases, namely, It was the ... and There was this .... In previous experiments, readers had shown better memory for concepts introduced by such phrases than they had when the same concepts were not focused (Birch $\&$ Garnsey, 1995). For instance, after reading a sentence such as la below, which focused the prime word street, readers were faster and more accurate at recognizing and naming a probe (STREET), both immediately and after a delay, than they were after reading a nonfocus sentence such as $1 \mathrm{~b}$ below (targets demarcated for example only).

1. (a) There was this /street/ nearby that really worried the young mother.

(b) The traffic on the /street/ nearby really worried the young mother. 
In the present study, we presented readers with such sentences and compared eye-movement patterns for focused concepts with those for their nonfocused counterparts.

\section{Method}

\section{Subjects}

Thirty native, English-speaking subjects from the University of Massachusetts participated in the experiment for course credit or for pay.

\section{Materials}

There were 100 pairs of sentences in the experiment, 50 experimental and 50 filler. The experimental sentences were all drawn from Birch and Garnsey (1995; see their appendix) and consisted of a focus and a nonfocus version in each pair. Examples appear in Pairs 1 (above) and 2 :

\section{2. (a) It was the /suburb/ that received the most damage from the ice storm. \\ (b) Workers in the /suburb/ hurried to restore power} after the ice storm.

In the focus versions ( $1 \mathrm{a}$ and $2 \mathrm{a}$ ), the target words (e.g., street and suburb) were placed within an It-cleft sentence or a There-insertion sentence ( 25 of each type of construction). In the nonfocus versions $(1 \mathrm{~b}$ and $2 \mathrm{~b})$, the targets appeared in a variety of syntactic positions, including object of a prepositional phrase, adjective within a noun phrase, direct object of the sentence, and subject of a relative clause. To reduce the likelihood that readers would skip then, the target concepts were at least five letters long.

In addition to the 50 pairs of experimental sentences, there were 50 pairs of two-line sentences that did not have a syntactic focusing construction; these served as fillers. Also, to ensure that subjects were paying attention to what they were reading, comprehension questions were constructed for 16 of the items. None of the questions emphasized the target words. For instance, the question following example sentences $2 \mathrm{a}$ and $2 \mathrm{~b}$ was Was the damage/power loss caused by a tornado?

\section{Design}

Placing the two versions of each sentence on separate lists resulted in two 100-item lists. Each target appeared in both focus and nonfocus versions of sentences so that comparisons between the two versions were of the same words. Of the experimental trials on both lists, half were in the focus condition and half were in the nonfocus condition. Each target appeared only once in each list, and each subject read only one list.

\section{Apparatus and Procedure}

To eliminate head movements during the experiment, a bite bar was prepared for each subject. Each subject was seated in front of a Sony Trinitron 1302 monitor, with his/her mouth resting on the bite bar. The subject was seated $62 \mathrm{~cm}$ from the monitor, which had 72 characters per line, four characters on the monitor subtending $1^{\circ}$ of visual angle. The SRI Dual Purkinjie Generation V eyetracker, which has a resolution of less than $10^{\prime}$ of arc, was interfaced with an Epson Equity III computer, which controlled text presentation and stored output.

To ensure accurate monitoring of subjects' eye movements, the eyetracker was calibrated for each subject. The subjects read 6 warm-up items and then 100 experimental and filler items. Each read each item at his/her own pace while the movements of the right eye was monitored by the eyetracker. After reading each item, he/she pushed a lever. Following $16 \%$ of the trials, there was a comprehension question which the subject answered YES or NO by pressing a lever on the response box. The experiment lasted about $40 \mathrm{~min}$.

\section{Results}

We report the effects of focus by examining eyetracking measures that reflect initial processing and measures that reflect reprocessing. The initial processing measures include number and duration of first-pass fixations, that is, the number of times and the amount of time a reader fixated a target region before moving past that region. The reprocessing measures include regressions and duration of fixations made in a region during rereading (i.e., secondpass reading time). Previous research (Ehrlich \& Rayner, 1983) has indicated that different reading measures reflect different types of comprehension processes. It is thought that gaze duration, that is, first-pass reading time for single-word target regions, reflects the amount of time spent carrying out lower level processing on the target word, including perceptual and semantic encoding (basically, lexical access) and some syntactic analysis. Other measures, including second-pass reading time, are thought to reflect higher level processing of the target. These higher level processes might include determining a word's information status (given-new) in the discourse; assigning it to its referent, if one already exists, or, if not, establishing a new referent in the discourse representation; and integrating it with preceding text and with contextually relevant knowledge (Ehrlich \& Rayner, 1983; see also Clark \& Haviland, 1977). Because our target regions in this experiment consisted of single words, we assumed that any focus effects on gaze duration indicated that focus influenced lexical access processes, whereas any focus effects on second-pass reading time indicated that focus influenced integration processes.

For the fixation-duration analyses, fixations of less than $100 \mathrm{msec}$ or greater than $1,000 \mathrm{msec}$ (i.e., outliers) were eliminated. For all analyses, we obtained means by subjects and by items for each condition, which were submitted to statistical tests.

\section{Initial Processing Effects}

If readers in this experiment were immediately sensitive to syntactic manipulations of focus, there should have been differences for focus and nonfocus conditions in the number of first-pass fixations and/or gaze duration (see Table 1, lines 1-2). For neither of these measures was there a difference between the two conditions. Subjects

Table 1

Pattern of Fixations for Target Concept by Condition

\begin{tabular}{|c|c|c|}
\hline \multirow[b]{2}{*}{ Measure } & \multicolumn{2}{|c|}{ Condition } \\
\hline & Focus & Nonfocus \\
\hline 1. Number of first-pass fixations & 1.04 & 1.05 \\
\hline 2. Gaze duration & $296^{*}$ & $302 *$ \\
\hline 3. Probability of regression out & .11 & .07 \\
\hline $\begin{array}{l}\text { 4. Probability of regression to } \\
\text { beginning of sentence }\end{array}$ & .30 & .16 \\
\hline $\begin{array}{l}\text { 5. Probability of Regression in } \\
6 \text {. Second pass reading time }\end{array}$ & .10 & .07 \\
\hline (counting nonregressions as 0 ) & $42^{*}$ & $29 *$ \\
\hline
\end{tabular}

Note-Target region includes only focused or nonfocused word, as in Examples 1 and 2. *Reading times, in milliseconds. 
made the same number of fixations and spent the same amount of time reading focus and nonfocus targets during first-pass processing (all $t \mathrm{~s}<1$ ). These results make clear that subjects did not spend a longer time reading a focused word when they first encountered it in a sentence.

\section{Reprocessing Effects}

Unlike the case for initial processing, there were differences between the focus and nonfocus conditions for the reprocessing measures. Note from line 3 of Table 1 that there was a higher probability that a regression would be triggered out of a focused region than out of a nonfocused region $\left[t_{1}(29)=2.13, p<.04 ; t_{2}(49)=2.44, p<.01\right]$. This result indicates that subjects were more likely to reread an earlier portion of a sentence (in this case, the beginning of the sentence) after reading a focus sentence than after reading a nonfocus one. This conclusion is supported by the result (see line 4 of Table 1) that the probability of making a regression into the first region of the sentence (i.e., into It was the or Workers in the in Pair 2 above) was about twice as high in the focus condition as in the nonfocus condition $\left[t_{1}(29)=4.63, p<.01 ; t_{2}(49)=4.4, p<\right.$ $.01]$. Note that this region contains fewer content words and is generally slightly shorter in the focus condition than in the nonfocus condition. Unless some other factor were operative, both of these facts would be expected to result in fewer regressions for the focus region. Reprocessing seems to have occurred in the focus condition over a broader region of the sentence, not just on the target itself.

There was a slightly higher probability of a regression from a later region of a sentence back to the focused word; this effect was, however, not significant [Table 1, line 5; $t_{1}(29)=1.6, p=.13 ; t_{2}(49)=1.6, p=.12^{1}$ ]. Second-pass reading time was longer on a focused target word than on a nonfocused target word [see line 6 of Table $1 ; t_{1}(29)=$ $\left.2.28, p<.03 ; t_{2}(49)=2.07, p<.04\right]$. Note that second-pass reading time, the duration of fixations in a target region during rereading, counts nonregressions as $0 \mathrm{msec}$, so that the probability of a second-pass reading (i.e., making a regression) is reflected within the measure.

\section{Follow-Up Analyses}

Because we used two types of syntactic focusing constructions, $I t$-clefts and There-insertion, we carried out post hoc analyses that included type of focusing structure as a variable. These analyses were to determine whether or not the pattern of results was the same for both types of focus structures. It turned out that the pattern of results was the same for both the $I t$-clefts and There-insertions for all measures except for probability of a regression back to the target concept (line 5 of Table 1). That is, for probability of a regression back to the target concept, there was an interaction between focus/nonfocus and type of focusing structure $[F(1,48)=$ $4.39, p<.05]$, reflecting the fact that $I t$-clefts showed a strong focus effect, but There-insertions did not. For the It -clefts, the probability of a regression back to the target concept was 13.28 for the focus condition and 7.12 for the nonfocus condition $[F(1,24)=8.55, p<.01]$; for There-insertions, the probabilities were 7.84 and 7.92 $(F<1)$. For number of first-pass fixations, gaze duration, probability of regression out, probability of regression to the beginning of the sentence, and second-pass reading time (lines 1-4 and 6 of Table 1), the pattern of effects was the same for both types of focusing structures (all $F \mathrm{~s}<1.4$ for the interaction between focus and type of focusing structure).

\section{Discussion}

These results show that readers were sensitive to syntactic manipulations of sentence focus: They were more likely to reread focused words than nonfocused, and they spent a longer time doing so. The extra processing that occurred in focus sentences appeared only in reprocessing and not in initial (first-pass) processing. These results indicate that focus affected the higher level processes involved in reading a word and not lexical retrieval. Syntactic constructions that emphasized a concept led to additional processing during reading, but only, apparently, after the reader had accessed the word and had begun integrating it into its context.

\section{EXPERIMENT 2}

In Experiment 2, the focus manipulation was based on question-answer pairs of sentences. This manipulation rests on the notion that a question signals an upcoming focus, and the answer to the question is perceived as being the focus of the sentence containing the answer (Chomsky, 1971; Cutler \& Fodor, 1979). A number of researchers have used question-answer pairs to manipulate focus (e.g., Bock \& Mazzella, 1983; Cutler \& Fodor, 1979). For instance, Cutler and Fodor presented their subjects with spoken dialogues such as that in Example 3. When the answer sentence in 3 was preceded by question a, the phrase on the corner was focused; when the answer sentence was preceded by question $\mathrm{b}$, blue was focused.

3. (a) Which man was wearing the hat?

(b) What hat was the man wearing?

The man on the corner was wearing the blue hat.

Cutler and Fodor found that phoneme detection was faster for the $/ \mathrm{b} /$ in blue when blue was focused than when on the corner was focused.

In this experiment, we used similar question-answer dialogues in written form. For each answer sentence in each dialogue, a target word or phrase either was or was not the focus of the sentence, depending on the question posed in the first sentence. As in Example 4 below, question a focused on a target phrase (in the underground bunker). Question $\mathbf{b}$ focused on a different region of the answer sentence, namely, a single word (cards; slashes appear in the example only):

\section{4. (a) Where were the soldiers?}


(b) What were the soldiers playing?

The soldiers /in the underground bunker/ were playing /cards/ to relieve their boredom.

Using such dialogues allowed us to measure focus effects in reading by a different mechanism than the syntactic focusing structures in Experiment 1. It also made it possible to keep the sentences identical across conditions. Furthermore, unlike in Experiment 1, there were two target regions in each answer sentence, one of which consisted of at least three words while the other consisted of a single word. This allowed us to explore focus effects on longer target regions as well as on single-word regions.

Method
Subjects
Thirty-two University of Massachusetts subjects, native English
speakers, participated in the experiment for course credit or for pay.

\section{Materials}

There were 36 pairs of experimental items and 48 filler items. The experimental items consisted of question-answer pairs as in Pair 4 (above) and Pair 5 below.

5. (a) What was the danger from?

(b) What might catch fire?

The danger from /the poisonous gases/ was that the /laboratory/ might catch fire.

In one condition, which will be referred to as the wide-focus case (version $a$ in Pairs 4 and 5), the question focused an entire phrase within the sentence. The phrase always consisted of a determiner, an adjective, and a noun, and sometimes also included a preposition (e.g., in in 4 above). In the second condition, the narrowfocus case (version $b$ in 4 and 5), the question focused a single word, which was a noun, a proper noun, or a specifier (e.g., twelve). The answer sentences were the same for both conditions. There were 48 filler items that did not have a question-focusing construction. Comprehension questions were written for 22 of the 94 items in the experiment to ensure that subjects were paying attention while they read.

\section{Design}

The two versions of each experimental item were placed on separate lists, and each target word or phrase appeared in both lists so that comparisons between conditions were of identical regions. Of the experimental trials on each list, half were in one condition and half were in the other. Each target word or phrase appeared only once in each list, and each subject read only one list.

\section{Apparatus and Procedure}

The procedure was the same as in Experiment 1. The same eyetracker used in Experiment I was interfaced in this experiment to an $\mathrm{ACl}$ computer that controlled text presentation and stored output. The View Sonic $17 \mathrm{G}$ monitor was $62 \mathrm{~cm}$ from the subject's face. With 72 characters per line of text, three characters subtended $1^{\circ}$ of visual angle. The session lasted about $35 \mathrm{~min}$

\section{Results}

The data were prepared for analyses as in Experiment 1 . We present the results for the two target regions separately and, for each, we report initial processing effects and reprocessing effects. Note that for the narrowfocus case, because the target region consists of a single word, the assumptions regarding reading measures and type of processing are the same as in Experiment 1. Thus, initial processing measures are assumed to reflect lexical access; reprocessing measures are assumed to reflect integration effects. For the wide-focus case, the target regions consist of several words and the foregoing correspondence between reading measures and processes does not apply to the region as a whole.

\section{Narrow Focus}

Initial processing effects. Consider first the results for the narrow-focus case (Examples $4 b$ and $5 b$ ), shown in lines $1-4$ of Table 2 . There were no reliable differences for the initial processing measures for the narrow-focus cases (lines 1-2). Subjects made approximately the same number of first-pass fixations, and gaze duration was the same in the two conditions (all $t \mathrm{~s}<1$ ). As with the syntactically marked focus regions in Experiment 1, narrow focus regions, as determined by preceding questions, were not processed more extensively during first-pass reading.

Reprocessing effects. Unlike the initial processing results, there were differences during reprocessing for the narrow-focus conditions (lines 3-4). There were more regressions from later in the sentence back into the narrow-focus region than there were when the same region was not focused $\left[t_{1}(31)=2.63, p<.02 ; t_{2}(35)=2.1, p<\right.$ $.05]$. Second-pass reading time was greater for the narrowfocus region ( $62 \mathrm{msec}$ ) than for the nonfocus region $\left[46 \mathrm{msec} ; t_{1}(31)=2.46, p<.02 ; t_{2}(35)=1.92, p<.06\right]$. Thus, subjects were more likely to spend more time reading a narrow-focus region than reading a nonfocus region, but only during second-pass processing. These results, like those from Experiment 1, indicate that lexical access is similar for focus and nonfocus conditions, but integration or higher level processes are taking longer in the focus case.

\section{Wide Focus}

Initial processing effects. We now turn to the results for the wide-focus case, where an entire phrase was the

Table 2

Pattern of Fixations for Target Region for Wide and Narrow Focus by Condition

\begin{tabular}{|c|c|c|}
\hline \multirow[b]{2}{*}{ Measure } & \multicolumn{2}{|c|}{ Condition } \\
\hline & Focus & Nonfocus \\
\hline \multicolumn{3}{|c|}{ Narrow Focus } \\
\hline 1. Number first-pass fixations & 1.01 & 1.03 \\
\hline 2. Gaze duration & $310^{*}$ & $316^{*}$ \\
\hline 3. Probability of regression in & .16 & .11 \\
\hline $\begin{array}{l}\text { 4. Second pass reading time } \\
\text { (counting nonregressions as } 0 \text { ) }\end{array}$ & $62^{*}$ & $46^{*}$ \\
\hline \multicolumn{3}{|c|}{ Wide Focus } \\
\hline 5. Number first-pass fixations & 2.46 & 2.24 \\
\hline 6. First pass reading time & $662^{*}$ & $618^{*}$ \\
\hline 7. Probability of regression in & .13 & .11 \\
\hline 8. Second pass reading time & & \\
\hline (counting nonregressions as 0 ) & $91^{*}$ & $89^{*}$ \\
\hline
\end{tabular}


focus of a sentence (see Examples 4a and 5a). From lines 5 and 6 of Table 2, it is clear that subjects made more first-pass fixations, and for a longer duration, in focus than in nonfocus regions. Both of these effects were reliable $\left[t_{1}(31)=3.99, p<.01\right.$, and $t_{2}(35)=3.49, p<.01$, for number of first-pass fixations; $t_{1}(31)=3.15, p<.01$, and $t_{2}(35)=3.69, p<.01$, for first-pass reading time]. Thus, subjects were carrying out extra processing in wider regions of sentences that were focused by a preceding question, and this extra processing occurred during firstpass reading.

Reprocessing effects. The results for reprocessing measures for wide focus are shown in lines 7-8 of Table 2 . The probability of a regression into a focused region was slightly, but nonsignificantly, greater than it was into a nonfocused region $\left[t_{1}(31)=1.37, p<.1 ; t_{2}<1\right]$. Second-pass reading time was slightly, but nonreliably, greater in the focus condition $[t \mathrm{~s}<1)$. These results suggest that the focused information was processed for longer, but primarily during first-pass rather than secondpass processing.

\section{Discussion}

The results from Experiment 2, where a question marked the focus in the target sentence, indicate that readers carry out additional processing in focused regions of sentences. However, in this experiment, the locus of the additional processing depended on the size of the focus region. When the question identified a single word as the focus, subjects made more regressions to the word and had longer second-pass reading times than they did when the same word was not focused. As with the results for syntactic focus in Experiment 1, the increased processing that occurred in the narrow-focus regions appeared only in reprocessing, not during firstpass processing. The results for the wide-focus case were different from the narrow-focus and syntactic focus cases. When a question identified a larger region (e.g., a prepositional phrase) as the focus of the target sentence, subjects spent a longer time reading this focused region than they did reading its nonfocused counterpart during first-pass processing but not during second-pass processing. This result suggests that subjects were able to realize that the region was the focus before they reached the end of it. This realization apparently led them to slow down and read more carefully, resulting in more fixations and longer first-pass reading times in the focused region.

In Experiment 2, then, the length of the focus region as defined by a preceding question seems to have determined whether additional processing would occur during the first pass through the region or after the subject had read beyond the region. When the focus region was wider, subjects may have had the chance to slow down and carry out the extra integration processes before reading beyond the region, whereas in the narrow-focus cases the slowdown occurred after their eyes had left the region.

\section{GENERAL DISCUSSION}

The results of these two experiments show that readers are sensitive to manipulations of sentence focus, as reflected in their eye-movement patterns. For syntactically marked focus (Experiment 1) and for a questiondefined narrow focus (Experiment 2), there were no first-pass effects, but readers made more regressions to the item that was focused than they did to when it was not focused, and they spent more time rereading it. These results are consistent with those of Rayner, Garrod, and Perfetti (1992), who found that discourse focus facilitated recovery from syntactic misanalyses but did not prevent the initial misanalysis of a garden-path sentence. Their results, along with our own, suggest that focus seems to influence integration rather than lexical access processes during reading.

When a preceding context established a wider focus in a subsequent sentence (Experiment 2), readers were slower during first-pass processing than during reprocessing. Apparently for this case, unlike the other two, readers began to make use of the contextual information identifying the focus before reading beyond the larger focused region, so that the additional processing was carried out during the first pass through the region. The consistent finding for syntactically defined focus regions and question-defined focus regions, both wide and narrow, is that subjects engaged in additional processing either during first-pass reading or during rereading. The claims that subjects seem to spend a longer time processing focused information when they first encounter it (Conrad \& Rips, 1986; Zimmer \& Engelkamp, 1981) and seem to process it "with a greater intensity" (Engelkamp \& Zimmer, 1982, p. 465) are verified by these eyetracking results.

Our results can also help explain findings that readers are more likely to detect erroneous information when it is the focus of the sentence than when it is not. Bredart and Modolo (1988) tested the limits of the "Moses illusion," in which subjects fail to detect an erroneous name in a statement (e.g., "How many animals of each kind did Moses take on the ark?" yields the answer "two" rather than "none; it was Noah, not Moses"). They found that the Moses illusion was less likely to occur when the erroneous name was the sentence focus (see also Bredart \& Docquier, 1989). In another study, subjects were also faster at responding to sentences that were inconsistent with a preceding paragraph when the inaccurate information was in the focus rather than the presupposition (Langford \& Holmes, 1979). Subjects seemed to be verifying the focused information first. Carpenter and Just (1977a) have proposed that linguistic devices such as cleft and pseudocleft sentences serve as "instructions" to readers that lead them to verify new (i.e., focused) information first and then integrate it with their discourse model. Our finding that readers spend a longer time pro- 
cessing the sentence focus, together with these results, suggests that the extra processing involves more careful analysis of the truth conditions, that is, of semantic interpretation of the sentence focus.

This more careful encoding of focused information can also help explain results from previous experiments that have examined memory for words during sentence comprehension. These earlier experiments showed that subjects were faster and more accurate when making recognition responses to focused words. This enhanced memory effect occurred both immediately after reading a sentence and after a delay (Birch \& Garnsey, 1995, Experiments 1 and 2). In another experiment (Birch \& Garnsey, 1995, Experiment 3), subjects were also faster at naming words that had been focused than words that had not. Since naming is thought to be a relatively pure measure of lexical access (e.g., Forster, 1981; Schustack, Ehrlich, \& Rayner, 1987), this result suggests that focused words are not only better remembered but are also more quickly retrieved upon a subsequent encounter. One benefit of more careful encoding of focused information, then, may be to make the focused referent more available for later processing, specifically to facilitate later reference to it. Additional processing during encoding may lead to an enhanced memory representation that yieids benefits in processing forthcoming information. The consequences of focus for memory representations seem to be due, in part, to differences in reading patterns for focused information.

The pattern of results for single-word regions helps to constrain the likely points in the reading process at which focus might be exerting an influence. That there were no focus effects on first-pass reading for these regions suggests that lexical access and initial syntactic assignment processes are similar for focused and nonfocused concepts during reading. The finding that there were focus effects on rereading for these cases suggests that higher level processes may require additional reading time and effort when a word is focused. The higher level processes that seem most relevant in our experiments include establishing and integrating a referent into the mental representation of a sentence and evaluating the item's significance with respect to its context. It may be that items that are syntactically or contextually focused become tagged in the mental representation as important or prominent. Perhaps evaluating this significance and representing that significance in the mental representation require additional processing during reading. In sum, focused words are not accessed more quickly initially, but they are more likely to be reread and to have longer rereading times than their nonfocused counterparts. The implication is that readers spend a longer time integrating a focused word with its context and perhaps into their mental representation of the sentence.

Our conclusion that focus does not seem to affect initial perceptual encoding or lexical access of the focused item during reading is contrary to the conclusions of some researchers investigating effects of focus in the auditory domain. Cutler (1976) and Cutler and Fodor (1979) have argued that words that have been focused by accenting are perceived more rapidly by listeners. It is possible that the disparity between their conclusions and ours can be attributed to domain differences. For auditory processing, unlike for reading, intonational cues play an important role in comprehension. The rhythmic cues in the prosodic contour of spoken discourse allow listeners to predict the locations of upcoming stressed words (Cutler, 1976; Shields, McHugh, \& Martin, 1974). Perhaps this predictability, which is probably less available during silent reading, facilitates perceptual encoding for accented/focused words. Additionally, accenting, which consists of increased pitch, vowel duration, and amplitude (Lehiste, 1970), seems to speed lexical access in and of itself (Cutler, 1976). It may be that the acoustic variables that are not present during reading can affect perceptual encoding of focused information. We should point out, however, that Cutler and Fodor (1979) also found faster detection times for focused information that was not accented. Thus, acoustic information alone probably cannot explain the disparity between their conclusions and our own.

Our conclusion regarding lexical access also differs from that of Blutner and Sommer (1988). They argued that focus influences the process of lexical retrieval during auditory comprehension. Their manipulation of focus was based on preceding questions, as in our Experiment 2 . It is possible that unknown differences between auditory and visual sentence processing are responsible for the discrepancy. Another possibility is that lexical decision, upon which they based their conclusion, is actually an inappropriate measure of lexical retrieval effects. It has been argued that, unlike naming, lexical decision is not a pure measure of lexical access (e.g., Forster, 1981; Schustack et al., 1987), so it is possible that the focus effects observed by Blutner and Sommer reflected effects on some process besides lexical retrieval.

While focus does not seem to affect initial lexical access during reading, it does seem to affect lexical access for subsequent references to a focused item. As mentioned earlier, a repeated presentation of a word that was focused in a preceding sentence yields naming times that are faster than those in the nonfocused case (Birch \& Garnsey, 1995, Experiment 3). Similarly, a pronominal reference to a word that was focused yields comprehension times that are faster than those for a word that was not focused (Ehrlich \& Rayner, 1983; Garrod, Freudenthal, \& Boyle, 1994). These findings, together with those from previously mentioned studies of memory (Birch \& Garnsey, 1995, Experiments 1-2; Carpenter \& Just, 1977b) and error detection (Bredart \& Docquier, 1989; Bredart \& Modolo, 1988), indicate that linguistic focus influences several levels of information processing during reading. Focus affects the way information is encoded. how well it is remembered, accessed, and evaluated, and how easily subsequent references to it can be made. 


\section{REFERENCES}

BERLYNE, D. E. (1958). The influence of complexity and novelty in visual figures on orienting responses. Journal of Experimental Psychology, 55, 289-296.

BerLyNE, D. E. (1966). Curiosity and exploration. Science, 153, 25-33.

BIRCH, S. L., \& GaRNSEY, S. M. (1995). The effect of focus on memory for words in sentences. Journal of Memory \& Language, 34, 232-267.

BlutNer, R., \& SOMmer, R. (1988). Sentence processing and lexical access: The influence of the focus-identifying task. Journal of Memory \& Language, 7, 359-367.

BOCK, J. K., \& MAZZELLA, J. R. (1983). Intonational marking of given and new information: Some consequences for comprehension. Memory \& Cognition, 11, 64-76.

Bredart, S., \& Docquier, M. (1989). The Moses illusion: A followup on the focalization effect. Cahiers de Psychologie Cognitive, European Bulletin of Cognitive Psychology, 9, 357-362.

BREDART, S., \& ModoLo, K. (1988). Moses strikes again: Focalization effect on a semantic illusion. Acta Psychologica, 67, 135-144.

CARPENTER, P. A., \& JUST, M. A. (1977a). Integrative processes in comprehension. In P. LaBerge \& S. J. Samuels (Eds.), Basic processes in reading: Perception and comprehension (pp. 217-241) Hillsdale, NJ: Erlbaum.

CARPenter, P. A., \& Just, M. A. (1977b). Reading comprehension as eyes see it. In M. A. Just \& P. A. Carpenter (Eds.), Cognitive processes in comprehension (pp. 109-139). Hillsdale, $\mathrm{NJ}$ : Erlbaum.

CHomsky, N. (1971). Deep structure, surface structure, and semantic interpretation. In D. D. Steinberg \& L. A. Jakobovits (Eds.), Semantics: An interdisciplinary reader in philosophy, linguistics, and psychology (pp. 183-216). New York: Cambridge University Press.

Clark, H. H., \& Haviland, S. E. (1977). Comprehension and the Given-New contract. In R. O. Freedle (Ed.), Discourse production and comprehension (pp. 1-40). Norwood, NJ: Ablex.

ConRaD, F. G., \& RiPs, L. J. (1986). Conceptual combination and the Given/New distinction. Journal of Memory \& Language, 25, 255-278.

Cutler, A. (1976). Phoneme-monitoring reaction time as a function of preceding intonation contour. Perception \& Psychophysics, 20, $55-60$.

Cutler, A., \& Fodor, J. A. (1979). Semantic focus and sentence comprehension. Cognition, 7, 49-59.

Ehrlich, K., \& RAYNER, K. (1983). Pronoun assignment and semantic integration during reading: Eye movements and immediacy of processing. Journal of Verbal Learning \& Verbal Behavior, 22, 75-87.

ENGELKAMP, J., \& ZIMMER, H. D. (1982). The interaction of subjectivization and concept placement in the processing of cleft sentences. Quarterly Journal of Experimental Psychology, 34A, 463-478.

Forster, K. I. (1981). Priming and the effects of sentence and lexical contexts on naming times: Evidence for autonomous lexical processing. Quarterly Journal of Experimental Psychology, 33A, 465-495.

Garrod, S., Freudenthal, D., \& Boyle, E. (1994). The role of different types of anaphor in the on-line resolution of sentences in a discourse. Journal of Memory \& Language, 33, 39-68.

GernsBaCher, M. A., \& Jescheniak, J. (1995). Cataphoric devices in spoken discourse. Cognitive Psychology, 29, 24-58.
Halliday, M. A. K. (1967). Notes on transitivity and theme in English, Part 2. Journal of Linguistics, 3, 199-244.

HoRnBY, P. A. (1974). Surface structure and presupposition. Journal of Verbal Learning \& Verbal Behavior, 13, 530-538.

LANGFORD, J., \& Holmes, V. M. (1979). Syntactic presupposition in sentence comprehension. Cognition, 7, 363-383.

LeHISTE, I. (1970). Suprasegmentals. Cambridge, MA: MIT Press.

Mackworth, N. N., \& Morandi, A. J. (1967). The gaze selects informative details within pictures. Perception \& Psychophysics, 2 , $547-552$.

RAYNER, K., \& DUFFY, S. A. (1986). Lexical complexity and fixation times in reading: Effects of word frequency, verb complexity, and lexical ambiguity. Memory \& Cognition, 14, 191-201.

Rayner, K., Garrod, S., \& Perfetti, C. A. (1992). Discourse influences during parsing are delayed. Cognition, 45, 109-139.

Rochemont, M. S., \& Culicover, P. W. (1990). English focus constructions and the theory of grammar. New York: Cambridge University Press.

Schustack, M. W., Ehrlich, S. F., \& RaYNer, K. (1987). Local and global sources of contextual facilitation in reading. Journal of Memory \& Language, 26, 322-340.

ScINTO, L. F. (1978). Relation of eye fixations to Old-New information in texts. In J. W. Senders, D. F. Fisher, \& R. A. Monty (Eds.) Eye movements and the higher psychological functions (pp. 175194). Hillsdale, NJ: Erlbaum.

Sedivy, J. C., Carlson, G. N., Tanenhaus, M. K., Spivey-Knowlton, M. K., \& EBERHARD, K. (1995). The cognitive function of contrast sets in processing focus constructions. Unpublished manuscript.

Shields, J. L., MCHugh, A., \& MarTin, J. G. (1974). Reaction time to phoneme targets as a function of rhythmic cues in continuous speech. Journal of Experimental Psychology, 102, 250-255.

SINGER, M. (1976). Thematic structure and the integration of linguistic information. Journal of Verbal Learning \& Verbal Behavior, 15 , 549-558.

Tanenhaus, M. K., Spivey-Knowlton, M. K., Eberhard, K., \& SeDIVY, J. (1996). Using eye movements to study spoken language comprehension: Evidence for visually-mediated incremental interpretation. In T. Inui \& J. McClelland (Eds.), Attention and performance XVI: Interaction in perception and communication (pp. 457478). Cambridge, MA: MIT Press.

Zimmer, H. D., \& ENGELKAMP, J. (1981). The given-new structure of cleft sentences and their influence on picture viewing. Psychological Research, 43, 375-389.

\section{NOTE}

1. This effect approached significance when the target region included the target word's determiner when the determiner was the same in both conditions $\left[t_{1}(29)=1.98, p<.06 ; t_{2}(49)=1.97, p<.06\right]$.

(Manuscript received October 31, 1995; revision accepted for publication May $24,1996$. 